\title{
La confianza ciudadana: un desafío para las instituciones electorales, de frente a las elecciones de 2012
}

The Public Trust: a Challenge for the Electoral Institutions, in Front of the 2012 Elections

\section{Armando I. Maitret*}

\section{Sumario:}

I. Introducción

II. El proceso que viene y una reforma que no se consolida

III. Un desánimo ciudadano en el Estado de México

IV. Los infortunios de las decisiones en relación con las nuevas reglas electorales

* Licenciado y maestro en Derecho por la UNAM, especialista en argumentación jurídica por la Universidad de Alicante, y profesor de Garantías Constitucionales en la Facultad de Derecho de la UNAM. 


\section{Resumen:}

En su trabajo el autor advierte que uno de los principales problemas que aquejan actualmente al sistema democrático de México es el preocupante descrédito que las autoridades electorales empiezan a generar en la ciudadanía. Desde su perspectiva, existen elementos para advertir, en un extremo, sus vínculos cada vez más íntimos y estrechos con la política, en un entorno en donde existe la percepción de que todo lo que toca la política se contagia de un grado de desconfianza que se propaga como si se tratase de una enfermedad; en el otro extremo, destaca que no puede negarse que las propias autoridades han propiciado a través de algunas de sus decisiones, una confusión en la ciudadanía respecto del rol que juegan, debido a que en ocasiones no queda claro si son garantes de la Constitución y la ley, o defensores de las causas de la clase política o de algún otro interés.

\begin{abstract}
:
In his work the author notes that one of the major problems facing the democratic system in Mexico is the alarming discredit generated by the electoral authorities on their citizens. From the population's perspective, there are elements that suggest increasingly close ties and links between the electoral authorities and political parties. This perception takes place within an environment in which politics is regarded as a rapidly spreading disease that infects everything it comes in contact with, with a great deal of mistrust. At the same time, electoral authorities themselves have created some confusion regarding their role given some previous ambiguous rulings. It is unclear whether they are guarantors of the constitution and the law, or act in the interest of the political elite.
\end{abstract}

Palabras clave: ciudadanía, instituciones electorales, elecciones, justicia electoral, desconfianza.

Descriptors: citizenship, electoral institutions, elections, electoral justice, distrust. 


\section{Introducción}

Sin duda alguna, el escenario que se vislumbra a tan solo unos cuantos meses de la celebración de los comicios de 2012, genera una enorme zozobra en cada uno de los que seguimos de cerca el constante quehacer de los actores y entes políticos, y es que uno de los mayores retos que les aguardan a las autoridades electorales en las futuras elecciones será tratar de recuperar la confianza que la ciudadanía ha venido perdiendo en la vida democrática e institucional del país, lo cual se ve reflejado en la disminución de la participación de los ciudadanos en las elecciones.

En el presente ensayo se tratará de mostrar que uno de los principales problemas que actualmente aquejan a nuestro sistema democrático es el preocupante descrédito que lamentablemente las autoridades electorales empiezan a generar en la ciudadanía, ${ }^{1}$ debido a que por un lado, se les ve íntimamente vinculadas con la política, y la percepción de que todo lo que toca la política se contagia de un grado de desconfianza se propaga como si se tratase de una enfermedad, y por el otro, las propias autoridades han propiciado, con algunas de sus decisiones, una confusión en la ciudadanía respecto del rol que juegan, pues a veces no queda claro si son garantes de la Constitución y la ley, o defensores de las causas de la clase política o de algún otro interés.

Cuando de elecciones se trata, tristemente reluce una tendencia gradual a la baja en la participación de la ciudadanía, y esto puede deberse a múltiples factores, como por ejemplo, la falta de información e interés en general, la ausencia de ofertas políticas serias que logren incitar al voto, la mucha o poca trascendencia de la elección, pero definitivamente, una de las razones a la que más debemos temerle tiene que ver con la pesadumbre que la política representa en la ciudadanía.

Esta falta de confianza que la política genera dentro de la población, es consecuencia inmediata del desprestigio público que tienen los partidos políticos en general -ocupan el antepenúltimo lugar en el índice de confianza ciudadana, con una calificación de 5.5 en una

1 Véase Monitor Mitofsky, Economía, Gobierno y Política, julio 2011, en http://www. consulta.mx/Estudio.aspx?Estudio=monitor-mitofsky, en la que se sitúa al IFE dentro de las instituciones con menor confianza promedio, con una calificación de 6.7. 
escala de 0 a $10-,{ }^{2}$ así como al desdoro ocasionado por el comportamiento, muchas veces indebido, de sus dirigentes y candidatos. De hecho, para el común denominador de las personas, tan solo mencionar que alguien es político o que está haciendo política no es ya bien visto del todo, lo cual sin duda debilita a cualquier sistema democrático.

Pero esto no termina ahí, pues en la actualidad, lamentablemente no basta sólo reprocharle a los partidos políticos el origen de este desprecio, cuando realmente existe una responsabilidad que desafortunadamente le concierne también a las autoridades, particularmente las electorales, quienes en muchas ocasiones no han estado a la altura de sobreponer los principios y reglas constitucionales a los intereses particulares de alguna clase política o poder fáctico, cuyas determinaciones no han sido consecuentes con las expectativas ciudadanas de aplicar las consecuencias jurídicas a quien haya violado la ley, con independencia de si se trata del presidente de la República, un gobernador de un estado, una televisora o un simple ciudadano. ${ }^{3}$

Es precisamente por lo anterior que una de las grandes tareas que tendrán las autoridades e instituciones electorales para el proceso que viene será reivindicar la magnífica imagen que en algún momento tuvieron ante los ciudadanos y que hoy se diluye cada día con el sentido de algunas de sus decisiones.

Me hago cargo de que la crítica inmediata a un posicionamiento de esta naturaleza, será que no se puede medir el papel de las instituciones con base en sólo algunas decisiones, sino que tendría que ser a partir del análisis de la totalidad de las mismas. ${ }^{4}$ Sin embargo, estimo que la objeción no es válida, porque hay de decisiones a decisiones, ya que no es lo mismo revisar, por ejemplo, y sin demeritar la importancia que pudiera tener la entrega de una credencial para votar con fotografía a un cierto ciudadano en determinadas condiciones, que aquellas en las que está en juego la defensa de una regla o principio constitucional, en los que obviamente están involucrados valores pro-

2 Cfr. Encuesta Nacional de Cultura Constitucional: legalidad, legitimidad de las instituciones y rediseño del Estado, México, IFE-UNAM, Instituto de Investigaciones Jurídicas, 2011.

3 Sobre el tema, véase Córdova Vianello, Lorenzo y Salazar Ugarte, Pedro (coords.), Democracia sin garantes. Las autoridades vs. la reforma electoral, México, UNAM, Instituto de Investigaciones Jurídicas, 2009.

${ }^{4}$ Cfr. Ochoa Reza, Enrique, en Seminario Instituciones Electorales a Debate: ¿crisis de confianza y legalidad?; Mesa 2. Tribunal Electoral del Poder Judicial de la Federación; jueves 9 de junio de 2011, en http://www.juridicas.unam.mx/vjv/participante.htm? $p=1411$ 
pios de nuestro sistema democrático, particularmente porque la salvaguarda de ellos le está encomendada a las propias instituciones del Estado, como el Tribunal Electoral del Poder Judicial de la Federación.

Sin detenernos más en estas cuestiones a las que preliminarmente nos hemos referido, pasemos ahora a analizar detalladamente algunos de los pormenores que actualmente tienen presencia en el devenir electoral y que de manera casi inevitable, de no corregirse ya, pondrán en riesgo el sano desarrollo del próximo proceso electoral.

\section{El proceso electoral que viene y una reforma que no se consolida}

No es menor la importancia que para el país entero tendrá la celebración de las elecciones de 2012, pues tan solo a nivel local, además de la renovación entera de las legislaturas y ayuntamientos en catorce estados de la República, ${ }^{5}$ se elegirán gobernadores en los estados de Chiapas, Guanajuato, Jalisco, Morelos, Tabasco y Yucatán, y asimismo, por lo que hace al Distrito Federal, habrá elecciones para renovar a todos los diputados de la Asamblea Legislativa, así como a los titulares de las dieciséis demarcaciones delegacionales y al titular de la jefatura de Gobierno; por lo que respecta a nivel federal, se renovarán por completo los 500 diputados y 128 senadores que integran el Congreso de la Unión, y se elegirá al próximo presidente de México.

Ahora bien, efectivamente, tal como se había adelantado en un principio, el conjunto de factores que afectan la situación real del país en materia de elecciones no es del todo alentador, ni mucho menos benéfico para desaparecer el desánimo ciudadano.

Para empezar, desde octubre de 2010 y hasta la fecha en que se escribe este ensayo, tenemos funcionando a un Instituto Federal Electoral (IFE) únicamente con seis de los nueve consejeros que integran el Consejo General. Aunque sería muy aventurado - y casi irresponsable- el tratar de predecir cuáles pudieran ser las consecuencias de esta conformación incompleta -o irregular-, pues desde el punto de vista técnico, pudieran o no ocurrir problemas relacionados con la

5 Campeche, Colima, Chiapas, Guerrero, Guanajuato, Estado de México, Jalisco, Morelos, Nuevo León, Querétaro, San Luis Potosí, Sonora, Tabasco y Yucatán. 
organización y dirección de una elección tan compleja como la que se avizora para el próximo año; sin embargo, sí se puede asegurar que esta circunstancia repercute perjudicialmente en el incipiente camino por el que el IFE atraviesa para tratar de reconstruir la credibilidad y confiabilidad que le fuera arrebatada en 2006.

Al respecto, no podemos olvidar que gracias a la falta de integración del Consejo General del IFE todavía se mantiene en suspenso lo que, en toda la historia electoral del país, pudiera ser la imposición de uno de los castigos económicos más ejemplares para un partido político por transgredir la prohibición para contratar o adquirir, por sí o por terceras personas, tiempos en cualquier modalidad de radio y televisión.

La sanción millonaria de la que se habla fue discutida por los seis consejeros electorales en la sesión pública del pasado 27 de abril, a causa de la responsabilidad acreditada del Partido Verde Ecologista de México (PVEM) por promocionar desmesuradamente su imagen y plataforma electoral en los anuncios publicitarios de las revistas Vértigo y TVyNovelas, así como en la telenovela Un gancho al corazón, donde uno de los actores portaba reiteradamente una camiseta con la leyenda Soy Verde, mismos que, respectivamente, fueron difundidos en los canales de televisión abierta de los que son concesionarias las empresas Televisión Azteca, S. A. de C. V. (TV Azteca) y Televimex S. A. de C. V. (Televisa). ${ }^{6}$

Al respecto, no obstante que los seis actuales consejeros del IFE tuvieron por demostradas las faltas cometidas por el PVEM, inesperadamente, al momento de votar el monto al que debería ascender la multa a imponer, se registró un empate en la votación de 3 consejeros a favor y 3 en contra, ${ }^{7}$ por lo cual, la discusión de la millonaria multa

${ }^{6}$ La denuncia de estos hechos desató el inicio del procedimiento de queja identificado con la clave Q-UFRPP 37/09 y sus acumulados Q-UFRPP 60/09 y Q-UFRPP 02/10, por la ilegal difusión de propaganda electoral a través de los tiempos en televisión. El proyecto de resolución que la Unidad de Fiscalización de los Recursos de los Partidos Políticos sometió a consideración del Consejo General del IFE, proponía imponer como sanción al partido político una sanción equivalente a los \$264178 439.78 (doscientos sesenta y cuatro millones ciento setenta y ocho mil cuatrocientos treinta y nueve pesos 78/100 moneda nacional).

7 Los consejeros Alfredo Figueroa Fernández, Benito Nacif Hernández y Leonardo Valdés Zurita, votaron a favor de imponer la sanción propuesta, en tanto que los consejeros María Macarita Elizondo Gasperín, Marco Antonio Baños Martínez y Francisco Javier Guerrero Aguirre lo hicieron en contra. 
se difirió hasta en tanto no se hiciere la designación de los tres consejeros que faltan por nombrar por parte de la Cámara de Diputados, pues cabe señalar que no existe previsión legal sobre un voto de calidad para el consejero presidente.

Si bien existe todavía la promesa inocua de que esta fallida discusión en algún momento habrá de retomarse, a mi consideración, es inaceptable que a casi ya tres años de haberse cometido este tipo de infracciones flagrantes a la Constitución y al Código Federal de Instituciones y Procedimientos Electorales (Cofipe) - según sostiene la propia autoridad electoral-, aún tengamos un partido político impune, pues con un proceso electoral que está a la vuelta de la esquina, esta situación se convierte en una invitación abierta para que cualquier partido promueva desde ahora mismo su imagen, programas y acciones, a través de menciones publicitarias en medio de telenovelas y programas deportivos, o en infomerciales transmitidos en radio $y$ televisión, en una completa y total transgresión de las disposiciones legales, a sabiendas de que probablemente no será sancionado.

Verdaderamente, la credibilidad que intenta retomar el IFE para estas elecciones que vienen, se encuentra en una posición cuesta arriba, y esto no es de extrañarse si partimos del supuesto de que también el sector empresarial y las concesionarias de radio y televisión se han encargado, muy a su manera, de demeritar su imagen públicamente, lo que podría también tener sus consecuencias en la confianza ciudadana en la institución y la posible disminución en la participación en las elecciones de 2012.

Tal es el caso de los ataques que recientemente ha recibido por parte de la Cámara de la Industria de la Radio y Televisión (CIRT), que de cierto modo, ha convertido lo que inició como un asunto netamente técnico, en una ola de acusaciones y denostaciones para el trabajo del IFE, particularmente al aprobar este último las reformas al Reglamento de Acceso a Radio y Televisión en Materia Electoral. ${ }^{8}$

La cuestión es muy sencilla, de acuerdo con estas reformas, en pocas palabras, ahora se acortaba el plazo del que disponían los concesionarios de radio y televisión para difundir los promocionales de los partidos políticos, que previamente hubieran sido aprobados y pautados por el IFE.

8 Aprobado por el Consejo General del IFE en sesión extraordinaria del 27 de junio de 2011, mediante la emisión del Acuerdo CG194/2011. El mencionado acuerdo fue publicado el 30 de junio siguiente, en el Diario Oficial de la Federación. 
Aunque no es el objetivo de este trabajo hablar acerca de la impugnación que presentó la CIRT en contra de estas modificaciones reglamentarias, ni de la decisión de la Sala Superior del TEPJF que revocó esas reformas reglamentarias —expulsándolas del sistema jurídico electoral que regirá para el proceso electoral de $2012-{ }^{9}$ salvo que el IFE, en un nuevo acuerdo decida, previa consulta a los sujetos regulados, fundar y motivar de mejor manera - en los términos señalados por los propios magistrados-, por qué los tiempos impuestos son técnicamente suficientes para que los concesionarios cumplan su obligación legal de trasmitir los spots que determine la autoridad electoral, ${ }^{10}$ lo que hay que destacar es que el tema sirvió para que desde esa industria se lanzara una campaña negativa, cuyo cometido principal es deslustrar al IFE.

Para muestra de ello, basta echar un vistazo al desplegado de prensa $^{11}$ que la CIRT publicó con motivo de la presentación de las impugnaciones que este grupo de concesionarios promovió ante la Sala Superior del Tribunal Electoral del Poder Judicial de la Federación (TEPJF), en donde se emiten expresiones tales como "Autoritarismo del IFE", "La radio y la televisión mexicana acuden al Poder Judicial Federal ante las arbitrariedades del IFE", "El IFE no tiene un solo peritaje técnico sobre la operación de la radiodifusión mexicana", "El IFE no tiene probado ningún sistema para el envío de spots a la radiodifusión mexicana" y "El IFE se apresuró en tomar decisiones que no pueden cumplir las estaciones locales de Radio pero tampoco las cadenas de radio y TV".

Cabe señalar que la resolución de la Sala Superior, aun cuando pudo modificar el acuerdo del IFE, asesorándose ella misma de peritos expertos y consultando a la propia industria de la radio y la televisión, cuáles son los tiempos adecuados para que técnicamente pudieran pasarse al aire los spots de los partidos políticos y las autoridades electorales, debe señalarse que fue una sentencia que debilitó aún más a la institución electoral frente al poder mediático, pues su fallo sirvió

9 Véase la sentencia emitida por la Sala Superior del Tribunal Electoral del Poder Judicial de la Federación el 14 de septiembre de 2011, en el expediente SUP-RAP-0146/2011 y sus acumulados. Uno de los efectos de dicha sentencia es que "debe regir el Reglamento de Acceso a Radio y Televisión en Materia Electoral, publicado en el Diario Oficial de la Federación el once de agosto de dos mil ocho".

10 Para una revisión crítica de la sentencia, véase Córdova Vianello, Lorenzo, "Fragilidad electoral", consultable en $h t t p: / / w w w . e l u n i v e r s a l . c o m . m x / e d i t o r i a l e s / 54786 . h t m l$

11 Disponible en: http://www.cirt.com.mx/ife-1107/110707-desplegado-cirt-ife.pdf. 
para que desde las televisoras y radiodifusoras se atacara nuevamente al IFE, siendo que dudo mucho que esa hubiera sido la intención también de los señores magistrados.

Se estima que era muy difícil para los magistrados generarse la sospecha de que eso sucedería. El poder de los medios y su animadversión a las nuevas reglas electorales que afectaron sus ingresos millonarios por la venta de publicidad electoral, provocó y seguirá provocando una reacción denostativa y de desprecio hacia las instituciones y el Estado de derecho particularmente por parte del duopolio televisivo de este país - Televisa y TV Azteca-, situación que pudo haber mitigado la Sala Superior, no sólo porque es la máxima autoridad jurisdiccional electoral del país, sino porque es un tribunal constitucional cuya misión fundamental es la salvaguarda y protección de las normas y principios constitucionales.

Para ello, se estima que en lugar de dictar una sentencia formal en la que se decide revocar una reforma reglamentaria por violaciones al procedimiento (no se hizo una consulta con los tiempos suficientes a la industria) y una indebida fundamentación y motivación - con el daño institucional al IFE frente a sus contrapartes poderosas-, debió haber entrado al estudio minucioso del fondo del asunto, hacerse llegar los estudios técnicos y de ser el caso, modificar la decisión del IFE - con lo que le hubiera dado también una lección por sus descuidos y faltas de cuidado en la toma de sus decisiones-, pero de esa forma también le hubiera dado cobertura a una importante institución del Estado mexicano frente a los ataques abiertos de los intereses económicos de la radio y la televisión.

Lo más desafortunado del revés al IFE es que sirvió a la industria de la radio y la televisión para intensificar su denuesto institucional debido a lo incómodas que le resultan las nuevas reglas electorales, con lo que se incrementa la merma en la percepción ciudadana sobre la autoridad electoral, en cuanto a la confianza de quién será nuestro árbitro electoral para 2012. Esta mala percepción es una de las razones - que no la única - por las que muchos ciudadanos se abstienen de votar, si se toma en consideración que la participación ciudadana ha ido constantemente a la baja, ${ }^{12}$ pues podría inferirse que no sólo ha

12 Cabe señalar que en la elección presidencial de 1994 votó el $77.16 \%$ de los ciudadanos inscritos en la lista nominal, en tanto que en el 2000 fue el 63.22\%, para que en el 2006 fuera sólo el 58.55\%; es decir, casi 19 puntos porcentuales a la baja, en el periodo de tres elecciones. Fuente: $h t t p: / / w w w . i f e . o r g . m x /$ portal/site/ifev2/Participacion_Ciudadana. 
perdido confianza en los partidos políticos, sino también en las instituciones electorales.

Por otro lado, debemos añadir también una serie de pendientes que nuestros legisladores nos han quedado a deber desde hace mucho, a efecto de darle vida en serio a temas muy relevantes de la reforma electoral de $2007,{ }^{13}$ los cuales habremos de analizar con un poco más detenimiento.

No obstante las dificultades y pendientes legislativos, es posible afirmar que gracias a dicha reforma electoral, contamos - al menos en el papel- con una coraza normativa mucho más sólida que antes; sin embargo, definitivamente su prueba de fuego la encontrará en las futuras elecciones, y uno de los retos más importantes, desde el punto de vista institucional, es recobrar la confianza de la ciudadanía.

Ya todos sabemos que la razón de ser de dicha reforma fue el gigantesco reto al que se vio sometida la democracia mexicana en la elección presidencial de 2006, pues con la intensa polémica que suscitó la controvertida spotización a la que jugaron tanto los actores políticos, como los principales medios de comunicación de radio y televisión, ${ }^{14}$ quedó más que demostrada la ineficacia del marco electoral vigente

13 Aprobada por el Congreso de la Unión el 6 de noviembre de 2007, cuyos efectos fueron que mediante decreto publicado en el Diario Oficial de la Federación el 13 de noviembre siguiente, se reformaran nueve preceptos de la Constitución Federal, y que por decreto publicado el 14 de enero de 2008, se expidiera un nuevo Código Federal de Instituciones y Procedimientos Electorales.

14 Sólo por recordar algunos de los promocionales o spots que marcaron la elección presidencial de dos mil seis, y que primordialmente Televisa y TV Azteca se encargaron de difundir, tenemos por ejemplo los utilizados por el Partido Acción Nacional (en adelante PAN) en contra de la coalición Por el Bien de Todos conformada por los partidos políticos de la Revolución Democrática (en adelante PRD), del Trabajo (en adelante PT) y Convergencia, cuyos lemas representativos fueron "Trabajas con Bejarano el de las ligas", "Mentir es un hábito para ti”, "López Obrador endeudará al país y a tu familia", "Maletas del dinero de Bejarano que fue a la campaña de Andrés Manuel López Obrador", "Si gana Andrés Manuel López Obrador te va a quitar tu casa y tu dinero", y también los empleados por la coalición referida en contra del PAN, entre los cuales están "Se afirma la existencia de negocios irregulares por parte de la familia Calderón-Zavala", "Cifras y flujogramas sobre las triangulaciones y negocios de los Zavala", "Los Calderón-Zavala evaden impuestos", "Los que están arriba no pagan impuestos, el cuñado de Felipe no paga impuestos y obtuvo 2 mil 500 millones de ingresos”, por citar los más destacados. Para abundar más al respecto, véase Luna Ramos, José Alejandro, "Los conflictos entre partidos durante las campañas electorales: una propuesta de ampliación a la jurisdicción electoral", Revista de la Facultad de Derecho de México, México, UNAM, núm. 247, enero-junio de 2007, pp. 40-44. 
en aquel entonces, lo que resultó en un detonante que sirvió para llamar la atención de los legisladores.

De manera inequívoca, puede decirse que una de las mayores consecuencias de la reforma fue la creación de un nuevo modelo de comunicación social de carácter político-electoral, que tuvo por motivo fortalecer y lograr una verdadera equidad en la contienda, al ser esta última uno de los principios rectores de mayor importancia para cualquier proceso democrático y que había cobrado una fuerza impresionante a partir de las elecciones presidenciales de 1994. Asimismo, con la reforma electoral de 2007 se quiso impedir que los intereses privados invadieran e impactaran de forma negativa las elecciones. ${ }^{15}$

Con miras a alcanzar uno de los principales objetivos de la reforma, los legisladores introdujeron, a medias, cuestiones muy importantes en la Constitución federal, cuyo desarrollo reservaron a la postre para la emisión de leyes reglamentarias.

Desde luego, se trata de las omisiones legislativas para emitir las disposiciones reglamentarias atinentes al ejercicio del derecho de réplica, contenido en el artículo 6o. constitucional, así como a las reglas a que debe sujetarse la propaganda gubernamental prevista en el artículo 134 constitucional. ${ }^{16}$

A pesar de que esta reforma constitucional entró en vigor hace más de tres años y medio, algo más importante debe estar pasando por la cabeza de los legisladores que integran el Congreso de la Unión, puesto que al día en el que se escriben estas líneas, no existe en nuestro sistema jurídico ni una ni otra ley reglamentaria.

Lo sorprendente de esta realidad, es que fueron ellos, los mismos legisladores, quienes se fijaron un plazo máximo para realizar la labor

15 Cfr. Córdova Vianello, Lorenzo, "Las razones y el sentido de la Reforma Electoral de 2007-2008”, Estudios sobre la reforma electoral 2007: hacia un nuevo modelo, México, Tribunal Electoral del Poder Judicial de la Federación, t. I, edición revisada, 2009, p. 58.

16 Según el Dictamen de las Comisiones Unidas de Puntos Constitucionales, y de Gobernación, la intención del legislador constituyente al establecer el derecho de réplica en el artículo 6o. constitucional, era elevar al rango de Ley Suprema el derecho de todas las personas para replicar informaciones que resulten contrarias a sus legítimos derechos, con la finalidad de establecer posteriormente en un ordenamiento secundario las reglas a seguir para el ejercicio de este derecho frente a los medios de comunicación social; mientras que la intención de adicionar tres párrafos al artículo 134 constitucional, era elevar al rango de norma fundamental las regulaciones a que debe sujetarse la propaganda gubernamental, de todo tipo, tanto durante las campañas electorales como en periodos no electorales, pp. 3 y 8. Disponible en: http://www.diputados.gob.mx/LeyesBiblio/proceso/ lx/055_DOF_13nov07.pdf. 
reglamentaria, ${ }^{17}$ y aun así, en materia de réplica sólo tenemos una propuesta de ley congelada en la Comisión de Gobernación de la Cámara de Diputados desde septiembre de 2009, y por lo que hace a las reglas en materia de propaganda gubernamental, ni siquiera tenemos una sola iniciativa de ley para su análisis y discusión.

En ese sentido, creo que será muy alto el precio que el IFE y el TEPJF habrán de pagar para saldar la deuda que esta negligencia legislativa le traerá a los próximos comicios, pues dejarles la responsabilidad de hacer en sus resoluciones y sentencias una labor que les correspondía a nuestros legisladores, volteará hacia los primeros la mira de todos los reflectores que esperarán con ansias la emisión de criterios endebles o contradictorios, y muy propicios para las campañas de descrédito diseñadas por los grandes consorcios televisivos y radiodifusoras y hasta de los propios partidos y sus candidatos.

Si ponemos atención, esta carencia reglamentaria ha dejado ver ya algunos de sus primeros efectos. Por ejemplo, para el ejercicio del derecho de réplica tenemos el paradigmático caso del recurso de apelación SUP-RAP-175/2009, resuelto por la Sala Superior del TEPJF el 26 de junio de 2009.

A grandes rasgos, en esta sentencia los magistrados de la Sala Superior, determinaron que el IFE tenía la facultad de velar por el respeto al derecho que tienen los ciudadanos y entes políticos legitimados para replicar cualquier información que afecte su imagen, dignidad, honra o reputación, lo que deberá hacer mediante la instauración de un procedimiento especial, en el que se integren y apliquen directamente las disposiciones contenidas en el artículo 6o. constitucional y en el párrafo 3 del artículo 233 del Cofipe, en aras de no dejar indefenso el derecho de replicar de quien se diga o sienta agraviado. ${ }^{18}$

Esta decisión es muy importante, pues el derecho de réplica es un derecho fundamental reconocido en el texto de la Constitución, por lo

17 De acuerdo con el artículo décimo transitorio del Cofipe, el Congreso de la Unión debió de haber expedido la ley reglamentaria del derecho de réplica a más tardar el 30 de abril de 2008, y en términos de lo dispuesto en el artículo tercero transitorio del Decreto de Reforma Constitucional publicado el 13 de noviembre de 2007, el Congreso de la Unión debió de haber realizado las adecuaciones correspondientes a las leyes federales en un plazo máximo de 30 días naturales contados a partir de su entrada en vigor.

18 Véase la tesis relevante VII/2010, aprobada por la Sala Superior del Tribunal Electoral del Poder Judicial de la Federación, por unanimidad de votos en sesión pública del 3 de febrero de 2010, que lleva por rubro: Derecho de RÉPliCa. Se tutela a través del PROCEDIMIENTO ESPECIAL SANCIONADOR. 
que si el legislador ha sido negligente en expedir la ley que reglamente su ejercicio, esto de ninguna forma lo vuelve nugatorio, ya que ante la carencia de una normativa reglamentaria que establezca un procedimiento específico para su ejercicio y protección, es deber y obligación de las instancias administrativas y jurisdiccionales electorales buscar la forma de solventar estas faltas legislativas.

En lo referente al tema de la propaganda gubernamental, podemos destacar la sentencia del recurso de apelación SUP-RAP-119/2010, resuelto por la Sala Superior del TEPJF el 24 de agosto de 2010, en donde los magistrados electorales determinaron que el actual presidente de la República - Felipe Caderón Hinojosa- infringió lo dispuesto en el artículo 41, Base III, Apartado C, párrafo segundo, de la Constitución federal, al difundir en cadena nacional propaganda gubernamental al mismo tiempo en el que los estados de Aguascalientes, Baja California, Chiapas, Chihuahua, Hidalgo, Puebla, Quintana Roo, Sinaloa, Tamaulipas, Veracruz y Zacatecas se encontraban en el periodo de reflexión al voto previo a la celebración de sus elecciones internas.

Sin embargo, los magistrados sostuvieron que el diseño imperfecto de la Constitución permite que el Ejecutivo Federal, a pesar de haber transgredido directamente la prohibición constitucional de difundir y transmitir propaganda gubernamental en tiempos no permitidos, no sea susceptible de ser sujeto de sanción y castigo, debido a que no existe en la Constitución ni en el Cofipe, un catálogo de sanciones a imponer al presidente de la República por violar la ley en esta materia.

Son este tipo de determinaciones las que vuelven confiable o no el trabajo de nuestras autoridades ante los ojos de una ciudadanía impaciente por volver a creer en ellas, como en las que en algún momento tuvimos y que, por ejemplo, sancionaron fraudes a la ley como los casos "Amigos de Fox", "Pemexgate" y que sujetó al control jurisdiccional los actos de los partidos políticos. Es de suma importancia el reto que tiene las autoridades electorales federales actuales, pues deben contrarrestar, con sus acciones consistentes y en defensa de la Constitución y sus principios, una peligrosa percepción de que a veces se da un paso y se retroceden dos.

Nadie se atrevería a cuestionar la nobleza de la reforma electoral de 2007, dado que la misma fue el resultado de un consenso de las fuerzas políticas, preocupadas por no volver a tener un proceso electoral como el de 2006, lleno de vicisitudes que marcaron una brecha en el camino que poco a poco intentamos corregir. Pero también debe se- 
ñalarse que no podremos lograrlo si no se toman las cosas en serio y se comienza a aplicar el real y verdadero sentido que tuvo esta reforma, y en eso sí que va la corresponsabilidad de las autoridades electorales, para proteger o garantizar los principios constitucionales en que se sustenta nuestra democracia, pues los partidos políticos y sus militantes o candidatos, como ya se ve por todos lados, hacen y harán todo lo posible por obtener triunfos electorales, aun situándose fuera de la ley o tratándo de defraudarla.

Ahí es donde las instituciones electorales, particularmente las de justicia - federal y local - están llamadas a defender la Constitución y sus principios, mediante decisiones debida y fuertemente argumentadas, en las que el centro de atención sea el interés nacional por encima de los intereses particulares de un determinado actor político o partido, o de los más oscuros intereses mediáticos o económicos. De no ser así, se estima, no habrá buenos incentivos institucionales para que los ciudadanos salgan a participar, con la consecuencia poco deseable, de mermar la calidad de nuestra democracia.

\section{Un desánimo ciudadano en las elecciones del Estado de México}

A diferencia de lo que muchos esperaban que fuera una elección presidencial preadelantada, los resultados que arrojó la jornada electoral del pasado tres de julio en el Estado de México, no muestran otra cosa más que un claro ejemplo de lo poco que incentivan las elecciones a la ciudadanía.

Lo que efectivamente fueron las elecciones más importantes y más costosas en nuestro país, por supuesto, después de las presidenciales que tendrán lugar en 2012, nos dan una alerta de lo que podría pasar en un futuro si permitimos que los partidos políticos continúen transgrediendo la ley y las autoridades electorales se queden como meras espectadoras, sin cumplir la función para la cual fueron creadas.

¿Por qué es que en este ensayo se alude al caso del Estado de México? Porque de acuerdo con el cómputo final que realizó el Instituto Electoral del Estado de México, de un padrón electoral compuesto por 10555352 electores, en estas últimas elecciones sólo votaron 4871275 ciudadanos; es decir, únicamente el $46.15 \%$ del total de los ciudadanos 
mexiquenses que podían votar tuvo interés en acudir a las urnas para elegir a su gobernante.

Numéricamente hablando, estos resultados representan un aumento en la participación ciudadana, pues si comparamos los porcentajes de votación que hubo para las elecciones a gobernador en el año de 2005, de un total de 8869630 de electores sólo votaron 3787332 ciudadanos, lo que es igual al $42.70 \%$ del total de los votantes registrados en aquel entonces. ${ }^{19}$

Aun así, sigue siendo muy pobre el porcentaje de participación ciudadana para lo que se supone fueron las elecciones más importantes a nivel estatal por cuanto a número de electores se refiere, ya que de ser cierto lo que muchos piensan, en el sentido de que las elecciones presidenciales serán un reflejo de lo que fueron las elecciones en el Estado de México, creo que estaríamos en serios problemas de confiabilidad, si tan sólo un poco más del $40 \%$ del total de votantes eligiera a nuestro próximo presidente, cuando el resto ni siquiera se interese en participar.

Ese aparente avance porcentual no significa que la credibilidad de la ciudadanía mexiquense se haya reconfortado, y es buen momento para que las instituciones electorales federales tomen nota del tema, ya que recobrar la confianza ciudadana es uno de los desafíos más importantes que tendrán que afrontar, lo cual sólo podrán hacer siendo garantes de la Constitución y sus principios, defensores del sistema democrático y de los derechos de los ciudadanos.

Por ejemplo, la justicia electoral tendrá su prueba de fuego al enfrentarse a su primer elección presidencial, donde tendrá que resolver las impugnaciones que presenten los partidos políticos no ganadores, donde alegaran mayormente como causas de nulidad de la elección actos anticipados de campaña, la utilización de recursos públicos destinados a las campañas electorales, y un malicioso bombardeo de infomerciales a través de las pantallas televisivas en diversos espacios que ya no se limitan sólo a los noticieros, sino que se difunden en programas deportivos, musicales, de cocina, etcétera, mismos que hasta el televidente más inexperto podría identificar como una promoción tendenciosa de ciertos gobernantes o personajes políticos, pero fuera de la ley.

19 Datos estadísticos obtenidos de la base de datos del Instituto Electoral del Estado de México, disponibles en: $h t t p: / / w w w . i e e m . o r g . m x /$ numeralia/result_elect.html. 
Cabe recordar que en la elección en el Estado de México, hubo una gran polémica por los 3528 spots publicitarios difundidos en todo el país (con excepción de Tlaxcala) en los canales de televisión abierta de TV Azteca y Televisa, referentes al Quinto Informe de Gobierno del todavía gobernador Enrique Peña Nieto.

Sobre el particular, vale señalar que el artículo 228, párrafo 5, del Cofipe, establece que el informe anual de labores o gestión de los servidores públicos (en este caso del gobernador Enrique Peña Nieto), así como los mensajes que para darlos a conocer se pueden difundir en los medios de comunicación social, y que no serán considerados como propaganda, siempre que la difusión se limite a una vez al año, en estaciones y canales con cobertura regional correspondiente al ámbito geográfico de responsabilidad del servidor público (en este caso el Estado de México) y no exceda de los siete días anteriores y cinco posteriores a la fecha en que se rinda el informe. En ningún caso la difusión de tales informes podrá tener fines electorales, ni realizarse dentro del periodo de campaña electoral (en ese caso, del 16 de mayo al 29 de junio).

Inicialmente, ante la denuncia que de estos hechos hizo el Partido Acción Nacional (PAN), el 18 de enero del presente año, el Consejo General del IFE emitió el acuerdo CG11/2011, en el cual determinó que el gobernador Enrique Peña Nieto, así como su coordinador general de comunicación social, eran responsables de transgredir claramente las disposiciones contenidas en los artículos 134 de la Constitución federal, y 228, párrafo 5, del Cofipe. Asimismo, se determinó que las televisoras TV Azteca y Televisa no tenían responsabilidad alguna en torno la difusión de estos spots a nivel nacional.

En contra de esta resolución, el Partido Revolucionario Institucional (PRI) y el entonces gobernador constitucional del Estado de México, promovieron un recurso de apelación ante la Sala Superior del TEPJF ${ }^{20}$ En la sentencia que al efecto emitió, cuya ponencia corrió a cargo de la entonces magistrada presidenta María del Carmen Alanís Figueroa, se resolvió por mayoría de cuatro votos, ${ }^{21}$ que el gobernador del Estado de México no tenía responsabilidad en los hechos denunciados, porque las televisoras, "generosamente" por no decir de una

20 Expedientes SUP-RAP-24/2011, SUP-RAP-26/2011, SUP-RAP-27/2011 y SUPRAP-32/2011, acumulados.

${ }^{21}$ En contra de eximir al gobernador votaron los magistrados Alejandro Luna Ramos, Salvador Olimpo Nava Gomar y Pedro Esteban Penagos López, quienes formularon un voto particular conjunto. 
manera ingenua, habían difundido los mencionados promocionales en casi todo el país, sin que se hubiera demostrado que esto fue por órdenes del PRI, del gobernador Peña Nieto, o de alguien de su gobierno, por lo que la Sala Superior revocó las sanciones impuestas a estos últimos y ordenó al IFE que individualizara las sanciones respectivas sólo por lo que respecta a la responsabilidad que le concierne a TV Azteca y Televisa.

El acabose de todo este entramado, tuvo su desenlace el 25 de mayo pasado, cuando tras una larga y también dividida discusión, el Consejo General del IFE le impuso una sanción a las televisoras en comento consistente en una apremiante y ejemplar amonestación pública.

Indiscutiblemente, el sentido de estas decisiones, constituyen un capítulo que incide de forma negativa en la confianza y en la percepción que los ciudadanos tienen de las autoridades electorales.

\section{Los infortunios de las decisiones en relación con las nuevas reglas electorales}

Los partidos políticos representados en el poder revisor de la Constitución fueron, si se permite decirlo así, los padres de la reforma electoral de 2007; sin embargo, no sé por qué razones, súbitamente ellos mismos desconocieron esa paternidad, y hoy parece que son los primeros en buscar vías alternas para deformarla y, si se puede mejor, evitar responsabilizarse de ella cuando ven de cerca el actuar de las autoridades electorales.

En los tres años que está vigente el nuevo sistema de comunicación política, muchos son los casos en los que los propios partidos políticos y sus miembros se empeñan en eludir las disposiciones constitucionales y legales surgidas a partir de la citada reforma, y son también muchos los casos en los que el IFE y el TEPJF, a través de sus resoluciones y sentencias, dejan sin sanción estas conductas, lo cual genera en la ciudadanía una percepción de impunidad que en nada contribuye en el respeto y confianza de las mismas instituciones.

Desafortunadamente, estos párrafos no alcanzan ni son suficientes para documentar todos los casos a los que me refiero, por lo que de aquí en adelante, sólo me referiré rápidamente a algunos de los más destacados, para evidenciar la serie de artificios, aunque ellos le lla- 
men "ingenio", de los que son capaces de realizar los actores políticos con tal de darle la vuelta a la reforma, esto es defraudar la ley.

1) Febrero de 2008. El alcalde de Naucalpan, José Luis Durán Reveles colocó propaganda en espectaculares y puentes peatonales con su fotografía y lemas alusivos a sus apellidos, tales como "En Naucalpan las obras PerDURAN" y "Para que te REVELES sano ante la vida", no obstante que el Código Electoral del Estado de México, recogiendo el sentido de la reforma al artículo 134 constitucional prohíbe la promoción personalizada de los funcionarios de gobierno con recursos públicos. No hubo sanción alguna.

2) Noviembre de 2008. La concesionaria Televisa transmite por más de una semana entera en su programa "Hoy", las atracciones de la Ciudad de México, donde conjuntamente con la promoción de los sitios, apareció en todos los programas la imagen del jefe de gobierno, Marcelo Ebrard, a veces cocinando, en otras simplemente platicando de cualquier cosa, pero difundiendo también su imagen ante una alta teleaudiencia. No hubo sanción alguna.

3) Febrero de 2009. Por dos días, TV Azteca y Televisa transmitieron por bloques enteros los promocionales de los partidos políticos, interrumpiendo incluso la transmisión en vivo de un encuentro de balompié mexicano, así como el juego del "Super Bowl”, en los cuales, colocaron una cortinilla al inicio de cada bloque en la que se leía "Los siguientes promocionales son ordenados por el IFE en cumplimiento a la Ley Electoral y se transmitirán hasta el 5 de julio", con lo cual se pretendió - con cierto éxito- denostar a la institución electoral, haciendo creer que se interrumpía había una afectación al televidente porque así lo había ordenado la autoridad electoral. El asunto concluyó con una "ejemplar" amonestación pública a las televisoras, poca cosa por el denuesto institucional. ${ }^{22}$

4) Marzo de 2009. De nueva cuenta TV Azteca y Televisa transmiten mensajes contratados para presuntamente difundir el informe de labores de los diputados del PVEM, aunque su contenido promocionaba lo mismo que su plataforma electoral - recuérdese que

22 Recurso de apelación identificado con la clave SUP-RAP-059/2009, resuelto por mayoría de votos de los magistrados integrantes de la Sala Superior del Tribunal Electoral del Poder Judicial de la Federación, en sesión pública del 22 de abril de 2009. 
de acuerdo con la reforma constitucional está prohibida la contratación en los medios electrónicos de todo tipo de propaganda electoral- El IFE multó a dicho partido con una sanción de más de 10 millones de pesos. El partido impugnó la resolución ante la Sala Superior del TEPJF, la cual revocó dicha sanción al determinar que los promocionales se encontraron dentro de la ley pues ellos contribuyeron a la formación de una opinión pública, sin que el contenido de tales informes incitara al voto a su favor. ${ }^{23}$

5) Mayo de 2009. Durante la transmisión en vivo a nivel nacional de la semifinal del torneo de clausura del balompié mexicano, aproximadamente al minuto 41 del primer tiempo, sin interrumpir el curso del partido, pero sí el audio, se insertó un recuadro del lado izquierdo de la pantalla, en el que un reportero de la empresa Televisa entrevistó al entonces candidato a jefe delegacional Demetrio Sodi, quien según se supo no era casual que estuviera en el estadio, pues días antes había publicado que tendría una entrevista durante ese partido de fútbol. A pesar de que el entrevistado hizo manifestaciones relativas a las acciones de gobierno que pondría en marcha en caso de resultar electo - actos de propaganda electoral-, la Sala Superior del TEPJF consideró que tal entrevista si bien constituyó propaganda electoral, la misma se realizó en un marco de legalidad al estar amparada por las libertades de expresión (del entrevistado) e información (del entrevistador). ${ }^{24}$ Sin embargo, para los especialistas de nueva cuenta fue un mecanismo en el que televisora y políticos eludían el cumplimiento de la ley, y la institución electoral no frenaba ese fraude.

6) Mayo de 2009. Las plataformas electorales del PVEM y de Nueva Alianza aparecen en los spots de la revista Vértigo difundidos en los canales de TV Azteca. Esa práctica continuó en 2011, con la

23 Recurso de apelación identificado con la clave SUP-RAP-087/2009 y acumulado, resuelto por unanimidad de votos de los magistrados integrantes de la Sala Superior del Tribunal Electoral del Poder Judicial de la Federación, en sesión pública del 8 de mayo de 2009.

24 Recursos de apelación identificados con la clave SUP-RAP-234/2009, SUPRAP-239/2009, SUP-RAP-240/2009, SUP-RAP-243/2009 y SUP-RAP-251/2009 acumulados, resueltos por unanimidad de votos de los magistrados integrantes de la Sala Superior del Tribunal Electoral del Poder Judicial de la Federación, en sesión pública del 4 de septiembre de 2009. 
promoción publicitaria de los gobernadores del Estado de México, Enrique Peña Nieto; de Jalisco, Emilio González, y de Nuevo León, Rodrigo Medina. No ha habido sanción por ello.

7) Mayo de 2009. El gobernador constitucional del Estado de México, Enrique Peña Nieto, apareció en el programa especial de televisión Mexicanas, Mujeres de Valor, transmitido en cadena nacional por señal abierta y repetido en múltiples estaciones de cable y señales afiliadas - en el que abiertamente se promocionó la imagen del gobernante-. El IFE calificó como infundada la queja; por su parte la Sala Superior del TEPJF confirmó tal resolución. ${ }^{25}$

8) Junio de 2009. Televisa promueve al PVEM a través de dos personajes de la farándula en la revista $T V y$ Novelas y en una telenovela - se trató de publicidad comprada por el partido para promocionarse en las revistas, pero al difundir la publicidad de éstas, se hacía referencia al contenido de los programas y estrategias del partido político, es decir, se defraudó de nueva cuenta la ley al supuestamente anunciarse en un medio impreso, pero promocionado en un medio electrónico-. El IFE posterga la resolución de las quejas presentadas en contra de estos hechos, por tener una votación dividida. En otras palabras, más de 2 años con impunidad.

9) Septiembre de 2010. TV Azteca y Televisa difunden 3528 spots publicitarios en todo el país (con excepción de Tlaxcala) con motivo del Quinto Informe de Gobierno de Enrique Peña Nieto -recuérdese que el Cofipe establece una excepción a la prohibición constitucional de que en la propaganda gubernamental se utilicen imágenes o sonidos de los gobernantes, que constituyan promoción personalizada, que consiste en que se puede hacer con motivo del informe de gobierno pero en el ámbito territorial que corresponda, en el caso al estado de México-. Después de que el IFE había impuesto una sanción al gobernador y al PRI, la Sala Superior del TEPJF determinó que dicho funcionario no tenía responsabilidad en los hechos denunciados, pues no le era imputable el "error" de las televisoras de difundir a nivel nacional esos spots, pues no había un contrato en donde así se hubiera

25 Recurso de apelación identificado con la clave SUP-RAP-231/2009, resuelto por unanimidad de votos de los magistrados integrantes de la Sala Superior del Tribunal Electoral del Poder Judicial de la Federación, en sesión pública del 26 de agosto de 2009. 
solicitado. ${ }^{26}$ Para la mayoría de los expertos, de nueva cuenta se trató de un fraude a la ley entre las televisoras y un político, auspiciado por la falta de sanción por la máxima autoridad electoral del país.

Los anteriores son sólo algunos de los asuntos más relevantes, además del de la CIRT ya citado con anterioridad, en los que pareciera que las instituciones electorales no han estado a la altura de las nuevas exigencias de la Constitución y de nuestra democracia, los cuales sin duda, han marcado el destino de la reforma electoral que, según parece, les estorba de sobremanera a la industria de la radio y la televisión y a los actores políticos; tan es así que su comportamiento denota un evidente fraude al sentido y razón de ser de lo que estos últimos crearon, pero lo más delicado parece ser que no hay autoridad que les ponga freno.

Aquí, sería conveniente preguntarnos por qué les pesa tanto a los partidos políticos cumplir con estas disposiciones que regulan el actual modelo de comunicación política, si finalmente, ellos mismos fueron quienes las propusieron y las volvieron obligatorias.

En mi opinión, si lo que los entes políticos quieren, al final de cuentas, es continuar posicionando su imagen en la mente del electorado a través de los espacios electrónicos de comunicación radiofónica y audiovisual -o no ver mermado el mercado tan jugoso de esa industria, económicamente hablando-, debido al poder de convencimiento y difusión que éstos han alcanzado dentro de nuestra sociedad, lo más conveniente para todos sería que modifiquen las reglas de tal modo que su actual comportamiento deje de estar defraudando la ley y haga pagar el costo de eso a las instituciones electorales.

De esta manera, tendríamos un marco normativo idóneo que les permitiría hacer y deshacer cuanto les plazca en los medios de comunicación, y asimismo, dejaría de quedar al descubierto la insuficiencia de nuestras autoridades en materia de justicia electoral para detener estas violaciones a la ley, pues ya no se verían en una encrucijada al momento de resolver asuntos trascendentales.

26 Recursos de apelación identificados con las claves SUP-RAP-24/2011, SUPRAP-26/2011, SUP-RAP-27/2011 y SUP-RAP-32/2011 acumulados, resueltos por mayoría de votos de los magistrados integrantes de la Sala Superior del Tribunal Electoral del Poder Judicial de la Federación, en sesión pública del 4 de mayo de 2011. 
A riesgo de caer en una exageración, ésta es la mejor salida que veo para detener este constante ir y venir que solamente afecta la imagen y confianza que los ciudadanos tienen de las instituciones electorales, una más difícil pero que sería la más deseable, es que nuestras autoridades electorales recobren el camino que con esas decisiones han perdido; que entiendan lo importante que son para los ciudadanos y para el sistema democrático. En sus manos está recobrar algo de la confianza ciudadana, de cara a las elecciones del 2012. Ése es su reto más importante, porque para cumplirlo se necesita actuar bien - según la Constitución y sus principios- en todo lo que se les presente. 